\title{
Effects of exposure to fine particulate matter in elderly hospitalizations due to respiratory diseases in the South of the Brazilian Amazon
}

\author{
A.B. Machin ${ }^{1}$, L.F. Nascimento ${ }^{1,2}$, K. Mantovani ${ }^{3}$ and E.B. Machin ${ }^{4}$ \\ ${ }^{1}$ Faculdade de Engenharia de Guaratinguetá, Universidade Estadual Paulista Júlio de Mesquita Filho, Guaratinguetá, SP, Brasil \\ ${ }^{2}$ Programa de Pós-Graduação em Ciências Ambientais, Universidade de Taubaté, Taubaté, SP, Brasil \\ ${ }^{3}$ Faculdade de Tecnologia de Guaratinguetá (FATEC), Guaratinguetá, SP, Brasil \\ ${ }^{4}$ Departamento de Ingeniería Mecánica, Facultad de Ingeniería, Universidad de Concepción, Concepción, Chile
}

\begin{abstract}
Exposure to air pollution is an important cause of hospital admissions due to respiratory diseases. Nevertheless, few studies use pollutant concentration data estimated by mathematical models. A time-series ecological study was developed, using data from hospitalizations due to respiratory diseases in people over 60 years of age, residents of Cuiabá, Brazil, during 2012, obtained from the Brazilian Ministry of Health. The independent variables were the concentrations of fine particulate matter $\left(\mathrm{PM}_{2.5}\right)$ and carbon monoxide (CO) estimated by mathematical modeling, minimum temperature, and relative humidity (obtained from the Brazilian Meteorological Agency), and the number of forest fires. The generalized linear regression model of Poisson was used, with lags of 0 to 7 days. The coefficients obtained were transformed into relative risk of hospitalization, with respective $95 \%$ confidence intervals; alpha=5\% was adopted. In that year, 591 hospitalizations were evaluated, with a daily average of $1.61(\mathrm{SD}=1.49)$, the $\mathrm{PM}_{2.5}$ average concentration was $15.7 \mu \mathrm{g} / \mathrm{m}^{3}$, and the CO average concentration was 144.2 ppb. Significant associations between exposure to these contaminants and hospitalizations in lags 3 and 4 in 2012 were observed. There was a hospitalization risk increase of $31.8 \%$, with an increase of $3.5 \mu \mathrm{g} / \mathrm{m}^{3}$ of PM 2.5 concentrations and an increase of 188 in the total number of hospitalizations, with an expense of more than $\approx$ US $\$ 96,000$ for the Brazilian Public Health System. This study provided information on the cost of air pollution to the health system and the feasibility of using a mathematical model to estimate environmental concentration of air pollutants.
\end{abstract}

Key words: Air pollutants; Particulate matter; Respiratory diseases; Elderly health; Mathematical modeling

\section{Introduction}

Respiratory diseases, diagnosed according to Chapter $X$ of the International Classification of Diseases, 10th Revision (ICD-10), were responsible for almost 323,000 hospitalizations of the people over 60 years of age in Brazil in 2012 generating costs for the Brazilian Public Health System (SUS) above R\$293,000,000 ( $\approx$ US\$ 150,000,000). More than 5,000 hospitalizations occurred in Mato Grosso state, generating costs close to $\mathrm{R} \$ 4,200,000$ ( $\approx$ US $\$ 2,200,000$ ); 591 hospitalizations were registered only in Cuiabá, MT, generating expenses to SUS above the R\$590,000, $\approx$ US\$ 302,000 (1).

Recent studies have evaluated the adverse effects of air pollutants on the health of the population, including mortality rates, hospital admissions, and emergency room visits in hospitals because of cardiovascular, respiratory, and other diseases (2-9). Other studies have shown that high levels of air pollution increase morbidity and mortality rates (10).
Particulate matter (PM) is a mixture of liquid and solid particles suspended in air, of which composition and size depend on the emission sources. These particles are classified into two groups: particles with a diameter between 2.5 and $10 \mu \mathrm{m}$ called coarse mode and particles with a diameter of less than $2.5 \mu \mathrm{m}$ called fine particulate that represent about 60 to $70 \%$ of the amount of $\mathrm{PM}_{10}(11,12)$. Carbon monoxide has an affinity for hemoglobin 240 times greater than oxygen, which causes a small amount of $\mathrm{CO}$ to saturate a large number of hemoglobin molecules, reducing the ability of the blood to carry $\mathrm{O}_{2}$. It also acts by diverting the dissociation curve of hemoglobin to the left leading to a decrease in $\mathrm{O}_{2}$ release in tissues. Automotive vehicles, industrial processes, biomass burning, among others, are pointed to as the main sources of emission of particulate matter and $\mathrm{CO}$ to the atmosphere, according to the World Health Organization (13). 
These pollutants are usually quantified by measuring stations of state environmental agencies. Nevertheless, not all states have environmental agencies, which can use mathematical models to estimate concentrations of air pollutants. An example of this model is Coupled Chemistry Aerosol and Tracer Transport model of the Brazilian developments in the Regional Atmospheric Modeling System (CCATT-BRAMS) $(14,15)$, already validated by Longo et al. (15). This model has been used operationally by the Center for Weather Forecasting and Climate Studies of the National Institute for Space Research (CPTEC/INPE) (16) and was used in previous studies (17-20).

The objective of this study was to identify the effects of exposure to fine particulate matter and $\mathrm{CO}$ on the number of hospitalizations due to respiratory diseases in elderly people residing in Cuiabá, Mato Grosso, a Brazilian state that does not have measuring stations of environmental agencies. The CCATT-BRAMS mathematical model estimated the values for the development of this study.

\section{Material and Methods}

An ecological time-series study was developed, with data related to hospitalizations due to respiratory diseases, such as pneumonia (J12.0-J18.9), bronchitis, and bronchiolitis (J20.0-J21.9), chronic obstructive pulmonary disease (J44.0-J44.9), and asthma (J45.0-J45.9), from ICD-10, in people of 60 years or older residing in Cuiabá, MT, Brazil. The values were obtained from the Department of Informatics of the National Health System (Datasus) (1). The studied period was from January 1, 2012 to December 31, 2012.

Cuiabá is the capital city of Mato Grosso state, with a population of approximately 600,000 inhabitants. It is located in the center of South America, at $15^{\circ} 36^{\prime} \mathrm{S}$ and $56^{\circ} 06^{\prime} \mathrm{W}$, so the climate is tropical (Figure 1 ). The rainy season is from October to April, the climate of the rest of the year is very dry. Cold fronts inhibit cloud formations, which causes constant forest fires. This city has a Human Development Index (HDI) of 0.785 and has 17 private hospitals and 11 hospitals that provide care for the SUS with about 1400 beds for hospitalization (21).

According to National Institute of Meteorology (INMET) (22), in the warmer month, the temperature can reach $40^{\circ} \mathrm{C}$ with average of $26^{\circ} \mathrm{C}$ and in the winter, the temperature can drop below $10^{\circ} \mathrm{C}$ due to the cold fronts coming from the south of the continent.

Pollution levels in Cuiabá are mainly determined by emissions from local industries, as well as a large number of forest fires recorded per year and the large fleet of vehicles over 400,000 (23).

CCATT-BRAMS is a mathematical model that allows numerical simulations of weather and climate, solving large phenomena explicitly on spatial scales and by parameterizing the processes that occur at scales smaller than the spatial resolution of the model. The Center for Weather

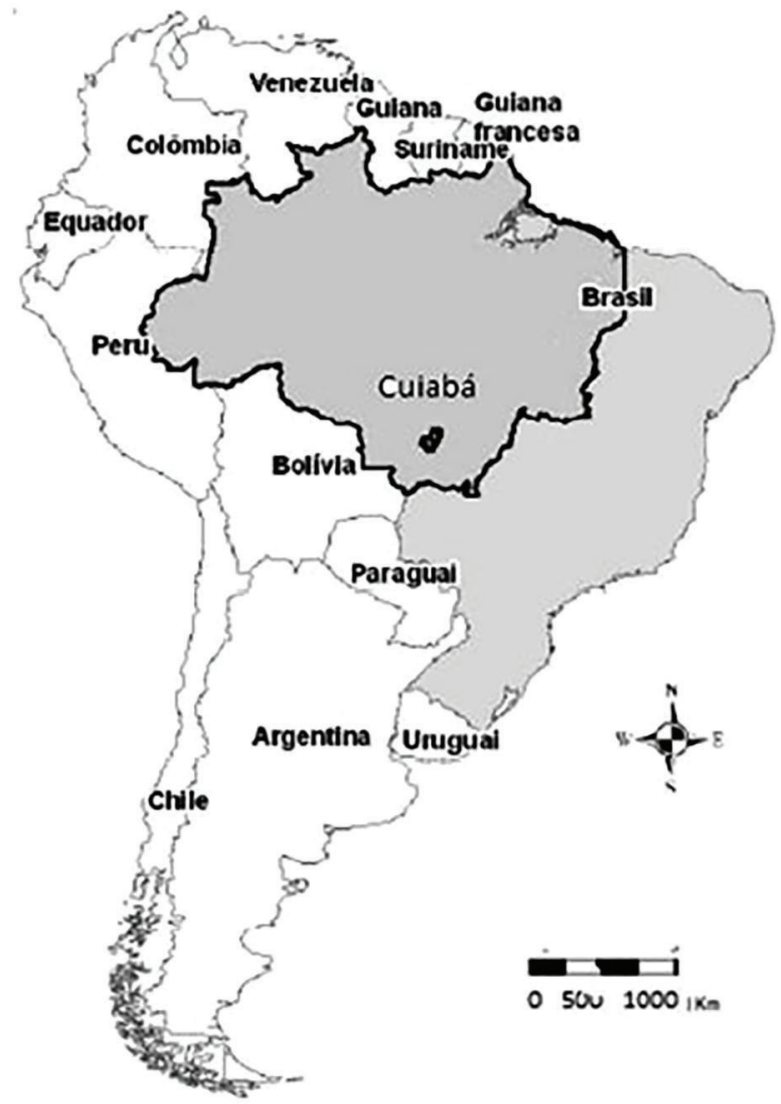

Figure 1. Geographic location of the municipality of Cuiabá, Mato Grosso state, Brazil.

Forecasting and Climate Research of the National Institute of Space Research (CPTEC-INPE) does this modeling process on a daily basis, producing daily diagnoses and predictions for up to three days, covering all of South America. The model takes into consideration transportation of various gases and aerosol particles, such as carbon monoxide (CO) and fine particulate matter $\left(\mathrm{PM}_{2.5}\right)$, which are estimated from the number and locations of fires outbreaks that are observed through remote sensors, thus generating daily estimates of various pollutants. The horizontal resolution of this operation is $25 \mathrm{~km}$ by $25 \mathrm{~km}$, with 38 atmospheric levels, of which the first level is from ground level to $40 \mathrm{~m}$ above the ground, and this method has already been validated. These records are estimated daily every $3 \mathrm{~h}(14,15)$.

The number of hospitalizations was obtained for the months of January and February of 2013 to identify the cases of November and December of 2012 that were reported in later dates.

The daily number of hospital admissions due to respiratory diseases was considered the dependent variable, the mean daily concentrations of $\mathrm{PM}_{2.5}$ and $\mathrm{CO}$ were estimated by the CCATT-BRAMS model and were 
considered the independent variables. The days of the week, holidays, number of days elapsed since the beginning of the period, daily mean temperature, daily mean relative air humidity, and forest fires, which may interfere directly or indirectly with respiratory diseases, were introduced as control variables in the models.

The daily data for forest fires were obtained from the Environmental Information System (SISAM), and information about air humidity and temperature was obtained from the INMET (22) in Cuiabá. The daily averages of $\mathrm{PM}_{2.5}$ pollutants and $\mathrm{CO}$ were calculated, being quantified in $\mu \mathrm{g} / \mathrm{m}^{3}$ and $\mathrm{ppb}$, respectively.

As the effects of exposure to pollutants can be noticed on the same day and subsequent days, a lag of zero to seven days (lag 0-lag 7) was used since there is no consensus on the extent of this period.

This analysis used the generalized linear model of Poisson regression. The coefficients provided by the model were transformed into relative risk (RR) of hospitalization according to the expression:

$$
\mathrm{RR}=\exp (\beta * \text { Conc })
$$

where $\beta$ is the coefficient obtained by Poisson regression and Conc is the pollutant concentration. The confidence interval $(95 \% \mathrm{Cl})$ for RR was also calculated.

The risk of hospitalization and the percentage increase of the risk was estimated according to the increase observed in the interquartile difference (IQD) between the 75th and 25th percentiles. The percentage change in risk was calculated by:

$$
\Delta \mathrm{RR}=[\exp (\beta * \mathrm{IQD})-1] * 100
$$

With the values of $R R$ according to IQD in the $P_{2.5}$ concentration, the proportional attributable ratio (PAR) was calculated using the following formula:

$$
\mathrm{PAR}=1-1 / \mathrm{RR}
$$

The PAR value shows the percentage increase in the risk of hospitalization and allows to estimate the number of hospitalizations associated with this increase through the population attributable fraction (PAF) obtained by the formula:

$$
P A F=P A R * N
$$

where $N$ is the number of hospitalizations of elderly patients with respiratory tract diseases, during the studied period.

After calculating the PAF, and knowing the average cost of the hospitalizations in the year ( $\approx$ US $\$ 500)$, it was possible to calculate the costs for the Public Health System that could be avoided with a decrease of IQD in the concentration of $\mathrm{PM}_{2.5}$. All analyses were performed using the statistical program Statistica v.7 (StatSoft, USA). The level of significance adopted in this study was $5 \%$.

This study was not submitted to an Internal Review Board (Ethics Committee) because the records are available in Datasus, a public website.

\section{Results}

During the study period, there were 591 hospitalizations of elderly due to respiratory diseases. The mean daily hospitalization was $1.61(S D=1.49)$ and ranged from 0 to 7 admissions. The mean concentration of $\mathrm{PM}_{2.5}$ was $15.7 \mu \mathrm{g} / \mathrm{m}^{3}$ $(\mathrm{SD}=3.2)$ and $\mathrm{CO}$ was $144.2 \mathrm{ppb}(\mathrm{SD}=52.3)$ (Table 1).

There were 20 days without values for $\mathrm{PM}_{2.5}$ concentration (5.5\% of the analyzed period). In addition, in 9 days $(2.5 \%)$, the mean concentrations of $\mathrm{PM}_{2.5}$ presented values above the limit considered tolerable $\left(25 \mu \mathrm{g} / \mathrm{m}^{3}\right)$.

Exposure to fine particulate material was significantly associated $(P<0.05)$ with hospitalizations due to respiratory diseases three and four days after exposure (lag 3 and lag 4) (Table 2).

Figures $2 \mathrm{~A}$ to $2 \mathrm{D}$ show the distribution of concentrations of fine particulate matter, $\mathrm{CO}$, daily number of hospitalizations, minimum temperature, and relative humidity of air in 2012. The largest concentrations of $\mathrm{PM}_{2.5}$ and $\mathrm{CO}$ were in the second half of the year, when temperatures, relative humidity, and rainfall are very low, and $98.01 \%$ of recorded fires occurred during this period, which potentiates the risk of hospitalizations.

The increase observed in the IQD between the 75th and 25 th percentiles was $3.5 \mu \mathrm{g} / \mathrm{m}^{3}$ for $\mathrm{PM}_{2.5}$.

Table 1. Concentration values of particulate matter $\left(\mathrm{PM}_{2.5}\right), \mathrm{CO}$, minimum temperatures, relative humidity and number of hospitalizations in Cuiabá, Brazil, 2012.

\begin{tabular}{lcc}
\hline & Mean (SE) & Min-Max \\
\hline Hospitalizations & $1.6(1.5)$ & $0-7$ \\
$\mathrm{PM}_{2.5}\left(\mu \mathrm{g} / \mathrm{m}^{3}\right)$ & $15.7(3.2)$ & $12.0-28.3$ \\
$\mathrm{CO}(\mathrm{ppb})$ & $144.2(52.3)$ & $69.0-317.1$ \\
Minimum temperature & $20.6(3.1)$ & $9.0-27.8$ \\
Relative humidity $(\%)$ & $70.4(13.7)$ & $35.0-96.0$ \\
\hline
\end{tabular}

Table 2. Coefficients with the respective standard errors provided by the Poisson regression model after 0 to 7 days of exposure to particulate matter $\mathrm{PM}_{2.5}$ ) pollutant and hospitalizations in Cuiabá, Brazil, 2012

\begin{tabular}{lrc}
\hline Lags & Coefficient & SE \\
\hline Lag 0 & 0.0567 & 0.0361 \\
Lag 1 & -0.0053 & 0.0366 \\
Lag 2 & 0.0530 & 0.0369 \\
Lag 3* & 0.0846 & 0.0380 \\
Lag 4* & 0.1095 & 0.0368 \\
Lag 5 & 0.0139 & 0.0382 \\
Lag 6 & 0.0441 & 0.0380 \\
Lag 7 & -0.0355 & 0.0370 \\
\hline
\end{tabular}

${ }^{*} \mathrm{P}<0.05$ 
A

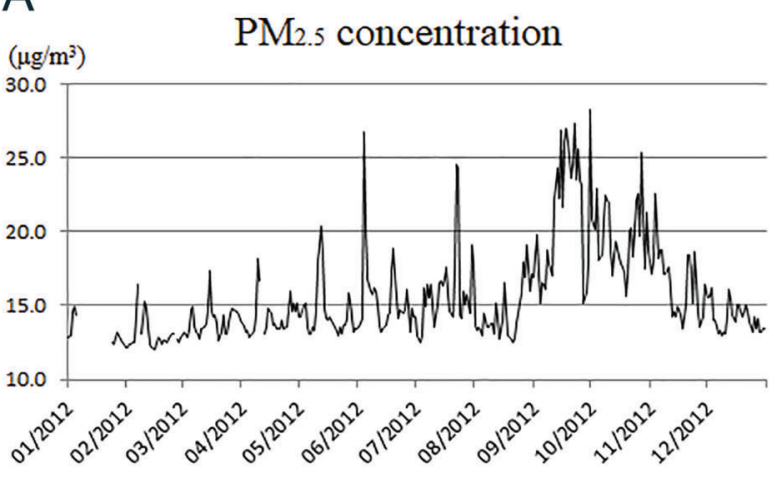

C

\section{Hospitalizations}

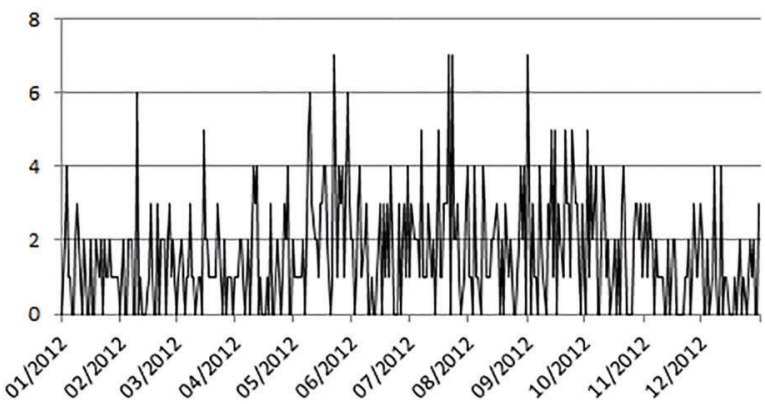

B

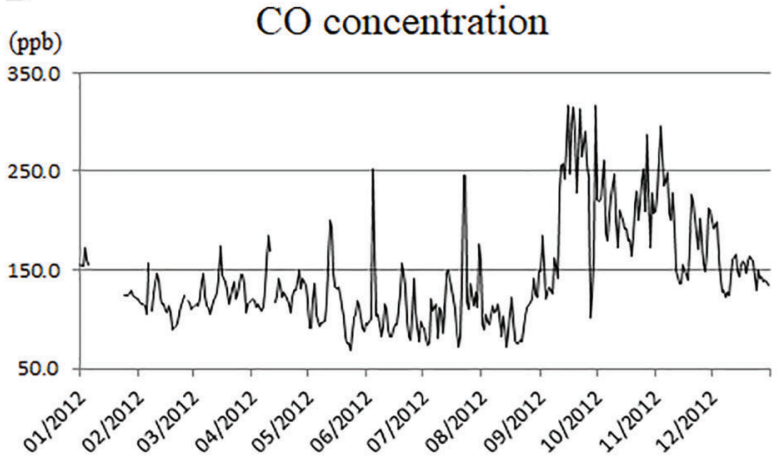

D Mean (Relative Humidity, Minimun Temperature and Forest Fires)

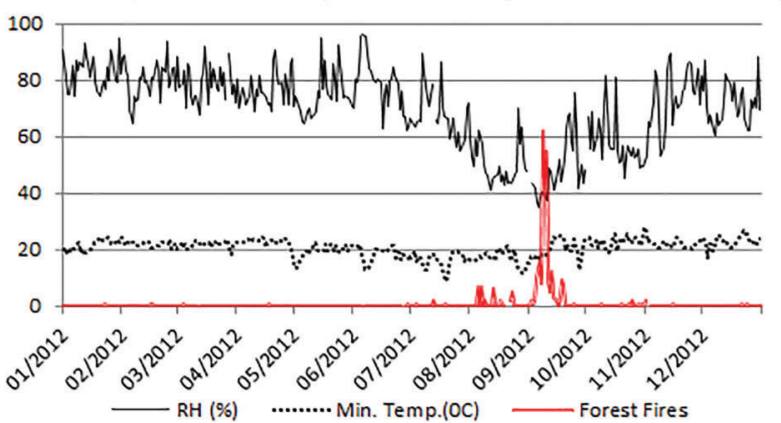

Figure 2. Temporal distribution of particulate matter $\left(\mathrm{PM}_{2.5}\right)(\mathbf{A})$; CO concentration (B); hospitalizations (C); minimum temperature, air relative humidity $(\mathrm{RH})$, and forest fires (D), in Cuiabá, MT, Brazil, 2012.

The relative risk of hospitalization after exposure to $\mathrm{PM}_{2.5}$ (Figure $3 \mathrm{~A}$ ), with an increase of $3.5 \mu \mathrm{g} / \mathrm{m}^{3}$ (Figure 3B), and percentage increase in relative risk (Figure $3 C$ ) were recorded. A significant association between exposure to $\mathrm{PM}_{2.5}$ and hospitalizations on the third day (lag 3, $R R=1.09$ ) and the fourth day (lag 4, $R R=1.12$ ) after exposure was found for the studied period, which allows a real view of the influence of air pollutant exposure on health outcomes.

Figure $3 C$ shows the percentage increase of RR of hospitalization and lag 3 and lag 4 were associated with hospitalizations, increasing the risk by $25.6 \%$ and $31.8 \%$, respectively. The increase of $3.5 \mu \mathrm{g} / \mathrm{m}^{3}$ in the $\mathrm{PM}_{2.5}$ concentration was used to calculate the number of additional hospitalizations, representing an increase of 188 elderly hospitalizations, which considering the average hospitalization daily value of $R \$ 998.71$, would increase the costs to the Public Health System by approximately $\mathrm{R} \$ 188,000$ ( $\approx$ US $\$ 96,000$ ). This indicates the importance of developing public policies to reduce the risks of pollution to the health of the population, especially of the elderly.

\section{Discussion}

There are few studies carried out in Cuiabá about the effects of air pollutants on hospitalizations of elderly of 60 years or older due to respiratory diseases. This study identified a significant association with exposure to $\mathrm{PM}_{2.5}$ in lags 3 and 4 and this increase would entail an increase in the cost for the SUS of approximately US $\$ 96,000$.

Another study carried out in Cuiabá in 2005 used this kind of analysis with data estimated by the CCATTBRAMS and found an association between exposure to $\mathrm{PM}_{2.5}$ and hospitalizations due to respiratory diseases in children under 5 years of age in lags 1,2 , and 5 for the whole year, and in the lags 1, 5, and 6 in the dry period (second semester), as a function of a $10 \mu \mathrm{g} / \mathrm{m}^{3}$ increase. Nevertheless, no association was found among elderly people over 60 years in the studied period. The daily mean annual and second semester values of $\mathrm{PM}_{2.5}$ concentration of that study were $7.5 \mu \mathrm{g} / \mathrm{m}^{3}$ and $11.9 \mu \mathrm{g} / \mathrm{m}^{3}$, respectively, which were lower than the values calculated in this study $\left(15.67 \mu \mathrm{g} / \mathrm{m}^{3}\right.$ and $\left.17.03 \mu \mathrm{g} / \mathrm{m}^{3}\right)$ (18). Those authors concluded that particulate emissions from forest fires in the 

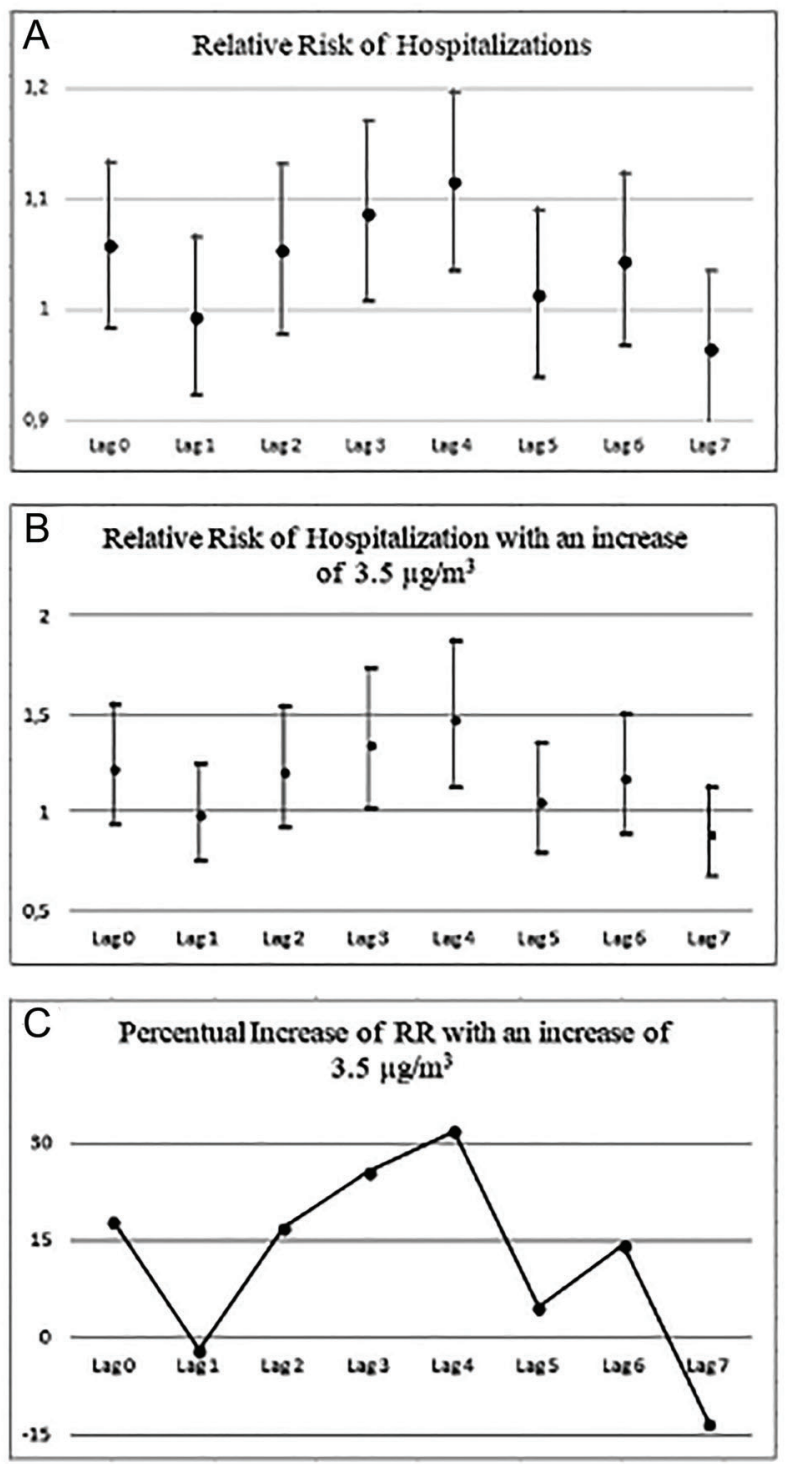

Figure 3. Relative risk (RR) of hospitalization after 0 to 7 days of exposure to particulate matter $\left(\mathrm{PM}_{2.5}\right)(\mathbf{A})$, with an increase of $3.5 \mu \mathrm{g} / \mathrm{m}^{3}$ (B), and RR percentage increase (C) in Cuiabá, MT, Brazil, 2012.

Amazon are related to the prevalence of hospitalizations due to respiratory diseases in sensitive population groups in the municipalities of Mato Grosso State. (18)

Some studies published in Brazil point to forest fires as responsible for health problems (24-27). The increase in the number of fires in the dry season of the year leads to significant increases in the levels of air pollutants, which translates into an increase in the number of hospitalizations due to respiratory diseases.

An ecological and exploratory study was conducted using data from the state of Mato Grosso from 2008 and
2009 on hospital admissions of children aged 0 to 4 years due to pneumonia and on fires in the same period. That study identified municipalities that required interventions to reduce rates of admission due to pneumonia and the number fires (26).

A time-series ecological study of children and elderly hospitalizations due to respiratory diseases was carried out in Alta Floresta and Tangará da Serra, Brazilian Amazon, using estimates of daily concentrations of $\mathrm{PM}_{2.5}$ resulting from the burning of biomass, and meteorological and calendar variables. The study identified significant increases in the relative risk of hospitalizations due to respiratory diseases in children for the whole year and for the dry period, with Lags of 3-4. For the elderly, the increase was significant for the current day in the dry season, with a $6.8 \%$ increase $(95 \% \mathrm{Cl}: 0.5-13.5)$ with a $10 \mu \mathrm{g} / \mathrm{m}^{3}$ increase of $\mathrm{PM}_{2.5}$ (24). Indicators of atmospheric pollution showed an association with respiratory disease occurrences in the Brazilian Amazon region, especially in the more vulnerable age groups, which may be used to assess the effects of forest fires on human health (25).

Another study related the effects of mean daily concentration and maximum hourly concentration of air pollution of fine particles $\left(\mathrm{PM}_{2.5}\right)$ with mortality in six cities of the Pearl River Delta in China (28). A significant association between the hourly peak of $\mathrm{PM}_{2.5}$ and mortality was identified.

Studies have shown that decreases in $\mathrm{PM}_{2.5}$ concentrations represent significant decreases in the number of hospitalizations and deaths due to respiratory, cardiovascular, and other diseases, as well as reductions in Public Health System costs (29). The concentrations of $\mathrm{NO}_{2}$ allow a better evaluation of the effects of air pollutants on respiratory health than the $\mathrm{PM}_{10}$ particles (30). In São José dos Campos, SP, a Brazilian city of medium size, the accumulated effect of eight days showed that for $24.7 \mu \mathrm{g} / \mathrm{m}^{3}$ increases in the mean concentration of $\mathrm{PM}_{10}$ there was an increase of $9.8 \%$ in hospitalizations (31). Other studies have shown that air pollution levels, generally represented by $\mathrm{PM}_{10}, \mathrm{PM}_{2.5}, \mathrm{NO}_{2}, \mathrm{SO}_{2}$, and $\mathrm{O}_{3}$ rates, are associated with the short-term increase in emergency room attendances due to respiratory problems (32-35).

Another study analyzed deaths due to respiratory diseases considering differential susceptibility according to sex using Poisson regression and identified an increase in the risk of death with exposure to $\mathrm{PM}_{10}$ (36).

Exposure to nitrogen oxides (NOx) emitted by burning fossil fuels was associated with deaths caused by respiratory diseases using data estimated by the CCATTBRAMS. Exposure to NOx was significantly associated with mortality owing to respiratory diseases: relative risk $(R R)=1.035$ for lag 2, $R R=1.064$ for lag 3, $R R=1.055$ for lag 4 , and $R R=1.042$ for lag 5 (19).

In addition, a study carried out in Taubaté, Brazil, identified only NOx to be associated with hospitalizations due to respiratory diseases, evidenced in lags 1 and 4 , 
and the RRs for hospitalization were $1.046(95 \% \mathrm{Cl}$ : 1.015-1.079) and 1.054 (95\% Cl: $1.054-1.196)$, respectively (20). Nevertheless, César et al. (17) studied the possible association between exposure to $\mathrm{PM}_{2.5}$ and hospitalizations due to pneumonia and asthma in the same period, but in children up to 10 years of age, and the relative risk of hospitalization values were significant for lags 0 and $2-5$. A 20.3 to $38.4 \%$ increase in hospitalization risk was observed when the concentration of $\mathrm{PM}_{2.5}$ was increased by $5 \mu \mathrm{g} / \mathrm{m}^{3}$, resulting in an increase of 38 hospitalizations.

This study may have some limitations; one of them may lie in the fact that fine particulate was estimated by mathematical modeling. Also, the force of the winds at the study site was not considered, which could dilute or increase the concentration of pollutants, bringing pollutants from regions near Cuiabá, which could alter the number of hospitalizations due to respiratory diseases. Another possible limitation is that, although data from hospitalizations were obtained from an official source (Datasus), it can contain diagnostic errors. In addition, it does not provide information on the nutritional status of the elderly, their medical history, living conditions, smoking status, among others that may be associated with respiratory diseases. The hospitalization data refers only to those occurring in the public network, excluding private hospitalizations, those from health plans, or health operators. Our findings should be used mainly for accounting

\section{References}

1. BRASIL. Ministério de Saúde - Datasus [homepage on the Internet]. Departamento de Informática do Sistema Único de Saúde [cited 2015 Nov 3]. Available at: http://tabnet. datasus.gov.br/cgi/tabcgi.exe?sih/cnv/nrmt.def

2. Gavinier S, Nascimento LFC. Particulate matter and hospital admissions due to ischemic heart disease in Sorocaba, SP. Rev. Ambient. Água 2014; 8: 228-236.

3. Guo Y, Jia Y, Pan X, Liu L, Wichmann HE. The association between fine particulate air pollution and hospital emergency room visits for cardiovascular diseases in Beijing, China. Sci Total Environ 2009; 407: 4826-4830, doi: 10.1016/ j.scitotenv.2009.05.022

4. Halonen JI, Lanki T, Yli-Tuomi T, Tiittanen P, Kulmala M, Pekkanen J. Particulate air pollution and acute cardiorespiratory hospital admissions and mortality among the elderly. Epidemiology 2009; 20: 143-153, doi: 10.1097/EDE.0b013 e31818c7237.

5. Nascimento LFC, Rizol PMSR, Medeiros APP, Fontoura IG. Association between concentrations of air pollutants and mean time of hospitalization due to pneumonia in children. Rev. Ambient. Água 2013; 8: 221-227, doi: 10.4136/ambiagua. 1400 .

6. Nascimento LFC, Francisco JB. Particulate matter and hospital admission due to arterial hypertension in a medium-sized Brazilian city. Cad. Saúde Pública 2013; 29: 1565-1571.

7. Amancio CT, Nascimento LF. Association of sulfur dioxide exposure with circulatory system deaths in a medium-sized purposes as it is not possible to establish a cause and effect relationship between exposure to pollutants and hospitalizations. However, an association between pollution and hospitalizations due to respiratory diseases was found, where exposure to $\mathrm{PM}_{2.5}$ and $\mathrm{CO}$ was statistically significant and may be considered a risk factor for respiratory diseases. It is important to emphasize that the study indicates an association rather than causality.

It was possible to find a statistically significant association between exposure to $\mathrm{PM}_{2.5}$ and hospitalizations due to respiratory diseases. It is also important to highlight the importance of using the CCATT-BRAMS model, which allowed the collection of pollutant concentration data in a region without a measuring station. The results presented should influence the development of public policies for the reduction of pollutants in the air, reducing costs for the SUS, as well as improving the quality of life of the general population.

\section{Acknowledgments}

This study was financed in part by the Coordenação de Aperfeiçoamento de Pessoal de Nível Superior, Brazil (CAPES; Finance Code 001). Luiz Fernando Nascimento is grateful to the National Council for Scientific and Technological Development (CNPq) for a Research Productivity Scholarship (process: 311109-2014-4). city in Brazil. Braz J Med Biol Res 2012; 45: 1080-1085, doi: $10.1590 /$ S0100-879X2012007500131.

8. Nascimento LF. Air pollution and cardiovascular hospital admissions in a medium-sized city in São Paulo State, Brazil. Braz J Med Biol Res 2011; 44: 720-724, doi: 10.1590/S0100879X2011007500079.

9. Machin AB, Nascimento LF. Effects of exposure to air pollutants on children's health in Cuiabá, Mato Grosso State, Brazil. Cad Saúde Pública [online]. 2018; 34: e00006617, doi: 10.1590/0102-311X00006617.

10. Santos UP, Terra-Filho M, Lin CA, Pereira LA, Vieira TC, Saldiva $\mathrm{PH}$, et al. Cardiac arrhythmia emergency room visits and environmental air pollution in Sao Paulo, Brazil. $J$ Epidemiol Community Health 2008; 62: 267-272, doi: 10.1136/jech.2006.058123.

11. Gomiscek B, Frank A, Puxbaum H, Stopper S, Preining O, Hauck $H$. Spatial and temporal variations of $\mathrm{PM}_{1}, \mathrm{PM}_{2.5}, \mathrm{PM}_{10}$ and particle number concentration during the AUPHEPproject. Atmospheric Environment 2004; 38: 3917-3934, doi: 10.1016/j.atmosenv.2004.03.056.

12. Slaughter JC, Kim E, Sheppard L, Sullivan JH, Larson TV, Claiborn C. Association between particulate matter and emergency room visits, hospital admissions and mortality in Spokane, Washington. J Expo Anal Environ Epidemiol 2005; 15: 153-159, doi: 10.1038/sj.jea.7500382.

13. WHO (World Health Organization). Air quality guidelines global update: report on a working group meeting. Geneva: 
World Health Organization; 2005. Available at: <http://www. euro.who.int/_data/assets/pdf_file/0008/147851/E87950. pdf $>$.

14. Freitas SR, Longo KM, Chatfield RP, Dias PP, Artaxo P, Andreae $\mathrm{MO}$ et al. The coupled aerosol and tracer transport model to the Brazilian developments on the regional atmospheric modeling system (CATT-BRAMS). Part 1: Model description and evaluation. Atmos Chem Phys Discuss 2009; 9: 2843-2861, doi: 10.5194/acp-9-2843-2009.

15. Longo KM, Freitas SR, Setzer A, Prins E, Artaxo P, Andreae MO. The coupled aerosol and tracer transport model to the Brazilian developments on the regional atmospheric modeling system (CATT-BRAMS). Part 2: model sensitivity to the biomass burning inventories. Atmos Chem Phys Discuss 2010; 10: 5785-5795, doi: 10.5194/acp-10-5785-2010.

16. BRASIL. Ministério da Ciências Tecnologia e Inovação. Centro de Previsão de Tempo e Estudos Climáticos do Instituto Nacional de Pesquisas Espaciais (CPTEC/INPE). Qualidade do ar. Disponível em: <http://meioambiente.cptec.inpe.br $>$. Accessed: 12 sept 2015 .

17. César AC, Nascimento LF, Mantovani KC, Vieira LC. Fine particulate matter estimated by mathematical model and hospitalizations for pneumonia and asthma in children. Rev Paul Pediatr 2016; 34: 18-23, doi: 10.1016/j.rpped.2015. 06.009.

18. Silva AM, Mattos IE, Ignotti E, Hacon Sde S. Particulate matter originating from biomass burning and respiratory. Rev Saúde Pública 2013; 47: 345-352, doi: 10.1590/S0034-8910. 2013047004410.

19. César AC, Carvalho. JA Jr, Nascimento LF. Association between NOx exposure and deaths caused by respiratory diseases in a medium-sized Brazilian city. Braz J Med Biol Res 2015; 48: 1130-1135, doi: 10.1590/1414-431X20154396.

20. Roman VVL, Carvalho JA Jr, Nascimento LF, César AC. Effects of air pollutants on respiratory diseases using estimated values by mathematical modelling of simulation. Rev Ambient Água 2015; 10: 825-831, doi: 10.4136/ambi-agua.1592.

21. BRASIL. Instituto Brasileiro de Geografia e Estatística (IBGE). Cidades. 2015. Available at: <http://cidades.ibge.gov. br/xtras/perfil.php?codmun=510340 $>$. Accessed March 16, 2016.

22. BRASIL. Instituto Brasileiro de Meteorologia (INMET). 2015. Available at: <http://www.inmet.gov.br/portal/>. Accessed April 23, 2016.

23. BRASIL. Departamento Estadual de Trânsito de Mato Grosso (DETRAN/MT). 2015. Available at: http://www. detran.mt.gov.br/adm/uploads/downloads/fdaf5frotademt2015.pdf. Accessed June 12, 2016.

24. Ignotti E, Hacon Sde S, Junger WL, Mourão D, Longo K, Freitas $S$, et al. Air pollution and hospital admissions for respiratory diseases in the subequatorial Amazon: a time series approach. Cad Saúde Pública 2010; 26: 747-761.
25. Ignotti E, Valente JG, Longo KM, Freitas SR, Hacon Sde S, Netto PA. Impact on human health of particulate matter emitted from burnings in the Brazilian Amazon region. Rev Saúde Pública 2010; 44: 121-130.

26. Nascimento LF, Medeiros AP. Admissions due to pneumonia and biomass burning: a spatial approach. J Pediatr (Rio J) 2012; 88: 177-183, doi: 10.2223/JPED.2161.

27. Oliveira BF, Ignotti E, Hacon SS. A systematic review of the physical and chemical characteristics of pollutants from biomass burning and combustion of fossil fuels and health effects in Brazil. Cad Saúde Pública 2011; 27: 1678-1698, doi: 10.1590/S0102-311X2011000900003.

28. Lin H, Ratnapradipa K, Wang X, Zhang Y, Xu Y, Yao Z, et al. Hourly peak concentration measuring the $\mathrm{PM}_{2.5}$-mortality association: Results from six cities in the Pearl River Delta study. Atmospheric Environment 2017; 161: 27-33, doi: 10.1016/j.atmosenv.2017.04.015.

29. Chen Li, Mengshuang Shi, Suhuan Li, Zhipeng Bai, Zhongliang Wang. Combined use of land use regression and BenMAP for estimating public health benefits of reducing $\mathrm{PM}_{2.5}$ in Tianjin, China. Atmospheric Environment 2017; 152: 16-23, doi: 10.1016/j.atmosenv.2016.12.023.

30. Leitte AM, Schlink U, Herbarth O, Wiedensohler A, Pan XC, $\mathrm{Hu}$ M. et al. Size-segregated particle number concentrations and respiratory emergency room visits in Beijing, China. Environ Health Perpect 2011; 119: 508-513, doi: 10.1289/ ehp.1002203.

31. Nascimento LF, Pereira LAA, Braga A, Módolo MCC, Carvalho Jr JA. Effects of air pollution on children's health in a city in Southeastern Brazil. Rev Saúde Pública 2006; 40: 77-82, doi: 10.1590/S0034-89102006000100013.

32. Arbex MA, Santos Ude P, Martins LC, Saldiva PH, Pereira LA, Braga AL. Air pollution and the respiratory system. J Bras Pneumol 2012; 38: 643-655, doi: 10.1590/S180637132012000500015.

33. Knol AB, Hartog JJ, Boogaard H, Slottje P, Van Der Sluijs JP, Lebret $\mathrm{E}$, et al. Expert elicitation on ultrafine particles: likelihood of health effects and causal pathways. Part Fibre Toxicol. 2009; 24:19-48, doi: 10.1186/1743-8977-6-19.

34. Stieb DM, Szyszkowiczl M, Rowe BH, Leech JA. Air pollution and emergency department visits for cardiac and respiratory conditions: a multi-city time-series analysis. Environ Health 2009; 8: 25, doi: 10.1186/1476-069X-8-25.

35. Tolbert PE, Klein M, Peel JL, Sarnat SE, Sarnat JA. Multipollutant modeling issues in a study of ambient air quality and emergency department visits in Atlanta. $J$ Expo Sci Environ Epidemiol 2007; 17: S29-S35, doi: 10.1038/ sj.jes. 7500625 .

36. Oliveira MS, Leon AP, Mattos IE, Koifman S. Differential susceptibility according to gender in the association between air pollution and mortality from respiratory diseases. Cad Saúde Pública 2011; 27: 1827-1836. 